\title{
Viajes y relatos de viajes. Variantes y nuevas posibilidades de un abordaje comparatista
}

\author{
Travel and Travel Reports. Variants and new Possibilities of a \\ Comparatist Approach
}

doi) doi.org/10.48162/rev.54.001

Elena Duplancic

Universidad Nacional de Cuyo

elguet@gmail.com

\section{Resumen}

El presente trabajo considera las modalidades más recientes de viajes como experiencias antropológicas y sus correspondientes relatos. Se menciona brevemente el estado de la cuestión en cuanto a los estudios sobre dichos textos. Desde un punto de vista teórico, se analiza tanto el viaje como el viajero y se ofrecen algunos ejemplos prácticos. En relación con los relatos, se enumeran sus contenidos, sus intenciones y sus funciones. Se deja planteada la influencia de los avances tecnológicos vinculados con la experiencia del extranjero a la distancia, así como con la aparición de nuevas textualidades audiovisuales que compiten con el relato. Se destaca el rol del lector de la literatura de viajes, se plantea como viajeros obligados a migrantes y exiliados y se señala a los periodistas como autores privilegiados de relatos de viajes.

Palabras clave: relato de viaje; literatura de viaje; viajero; viaje. 